American Journal of Applied Sciences 9 (2): 177-179, 2012

ISSN 1546-9239

(C) 2012 Science Publications

\title{
Dihydroartemisinin-Stimulated Hyperplasia of Rat Lung Smooth Muscles
}

\author{
Utoh-Nedosa Uchechukwu Anastasia \\ Department of Pharmacology and Toxicology, Faculty of Pharmaceutical Sciences, \\ Nnamdi Azikiwe University, P.M.B. 5025, Awka, Anambra State, Nigeria
}

\begin{abstract}
Problem statement: Dihydroartemisinin was shown to produce two types of inhibitory effects on the cardiac muscles of rats. It was also shown to stimulate haemopoiesis in the lungs, liver, spleen, intestine and kidney of rats. This study attempted to find out the nature of the effect of oral dihydroartemisinin on the lungs of Wistar albino rats. Approach: The effects of dihydroartemisinin on the tissues of the lungs of wistar albino rats were investigated with five doses of Dihydroartemisinin (DHA) administered for 5 days by oral intubation. The five tested doses were $1 \mathrm{mg} \mathrm{kg}^{-1}$, a repeated dose of 1, 2, 60 and $80 \mathrm{mg} \mathrm{kg}{ }^{-1}$ DHA. Results: Histopathological examination of the tissue micrographs of the lungs of the dihydroartemisinin treated rats showed that in comparism with those of the controls, DHA had no adverse effects on the tissues of the lungs of the rats but rather produced a direct stimulatory effect on the smooth muscles of the lungs. This stimulation caused hyperplasia of these tissues which was observable histologically in tissue micrographs of the lungs. These effects of dihydroartemisinin on the tissues of the lungs of Wistar albino rats were dose, repetition and time dependent. Conclusion: These growth hormone-like stimulatory effects of dihydroartemisinin on the smooth muscles of the lungs suggest that DHA enhanced the functioning capacity of the lungs of the DHA-treated rats. These results suggest that dihydroartemisinin has possible respiration enhancement effects.
\end{abstract}

Key words: Histopathological examination, smooth muscles, Dihydroartemisinin (DHA), wistar albino rats, tissue photomicrographs, malarial parasites, anatomical examination, maximal response dose, oral dosage regimens

\section{INTRODUCTION}

Dihydroartemisinin is acclaimed for its rapid clearance of malarial parasites in uncomplicated and complicated malaria. Little attention was paid to the organ effects of DHA in the past. However some recent studies reported the direct effects of dihydroartemisinin on the smooth muscles of the intestine of rats (Anastasia, 2011); on the smooth muscles of the bronchial tubes; (Uchechukwu et al., 2011).

On the coronary blood vessels 14 . Nedosa et al. (2011a); on cardiac smooth muscles (Anastasia et al., 2011) and on extrabone marrow sites of haempoies in rats (Nedosa et al., 2011b; Anastasia et al., 2012).

This study investigated the effects of oral dosage regimens of DHA on the lungs of Wistar albino rats.

\section{MATERIALS AND METHODS}

The test and control rats were weighed $10 \mathrm{~min}$ before the administration of the first dose and $10 \mathrm{~min}$ after the administration of the last dose of each of the five doses of DHA tested. Equivalent doses of distilled water to the administered doses of DHA were administered to the control rats in each experiment.

The tested doses of DHA were 1 and $1 \mathrm{mg} \mathrm{Kg}^{-1}$ which was repeated after an interval of 1 week, 2, 60 and $80 \mathrm{mg} \mathrm{Kg}^{-1}$. Young adult rats weighing $75-90 \mathrm{Kg}$ were given the repeated $1 \mathrm{mg} \mathrm{Kg}^{-1}$ dose while adult rats weighing 104-106 gr were given the remaining 4 doses of DHA tested. Five test and four control rats were used for each experiment. Each dose of DHA or distilled water was administered by oral intubation for 5 days. The rats given the repeated $1 \mathrm{mg} \mathrm{Kg}^{-1}$ dose received the treatment for 5 days, rested for 1 week and received the 5-day treatment again.

The test and control rats were sacrificed $24 \mathrm{~h}$ after the administration of the last dose in each experiment. Their lungs were then harvested and their tissue photomicrographs prepared through conventional methods.

\section{RESULTS}

The weight gain in the DHA-treated rats was greater than those of the control rats. It was dose 
dependent. The $2 \mathrm{mg} \mathrm{kg}^{-1}$ DHA-treated rats had the greater weight gain. Gross anatomical examination and comparism of DHA-treated and control rats showed that that DHA treatment had no adverse effects on the lungs of the test rats. Histopathological examination and comparism of the lung tissue of the DHA - treated and control rats showed that DHA treatment with the 5 dosage levels of DHA tested had no adverse effects on the tissues of the lungs of the treated rats. On the other hand, DHA treatment produced a direct dose, repetition and time dependent stimulation of the growth and proliferation of the smooth muscles of the lungs (Fig. 1). The $2 \mathrm{mg} \mathrm{kg}^{-1}$ DHA dose was the maximal response dose.
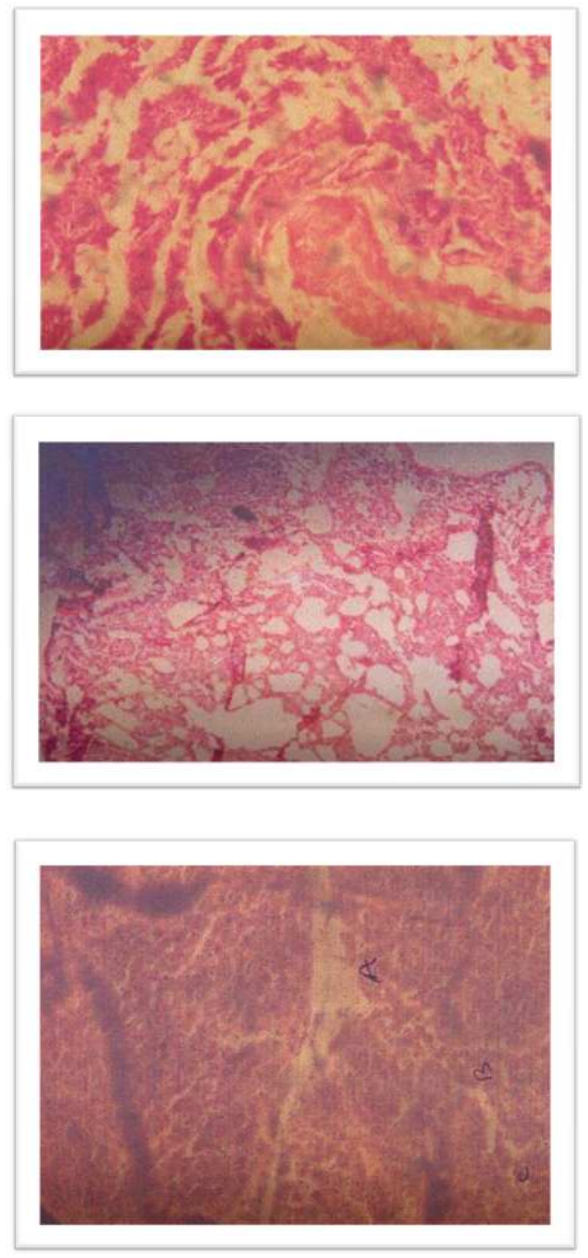

Fig. 1: The stimulatory effects of oral dihydroartemisinin on the smooth muscles of the DHA-treated rat lungs are shown in the 2 photomicrographs above while the photomicrograph of the lungs of the control rat is shown below

\section{DISCUSSION}

The direct stimulation of growth and proliferation of the smooth muscles of the lungs by dihydroartemisinin suggests that DHA strengthened the structural and functional status of the lungs. The dose and repetition dependent weight gain in the DHA treated rats which followed the same pattern as the proliferation of the lung smooth muscles supports our observations on the cell multiplication effects of DHA on the lung smooth muscles of the lungs.

The findings of this study suggest that dihydroartemisinin has direct growth hormone-like stimulatory effects on rat lung smooth muscles.

This has beneficial implications for the respiratory functional capacity of the malaria patient who is on DHA (artemisinin) treatment.

Artemisinin derivatives dihydroartemisinin and artesunate have been found to be very effective antimalarials (Dhingra et al., 2000; WHO, 1994; Cumming et al., 1997; Asawamahaskda et al., 1994; Woodrow et al., 2005). Since dihydroartemisinin and artesunate have potentials in inhibiting cancer tumor cell growth and angiogenesis (Kim et al., 1993; Efferth et al., 2001; 2002; Chen et al., 2003; Woerdebag et al., 1993; Lai and Singh, 1995; Singh and Lai, 2001).

\section{CONCLUSION}

The direct stimulant effects of dihydroartemisinin on the lung smooth muscles suggest that DHA might be of use in the treatment or prevention of lung cancer. Transferrin was found to overcome drug resistance to artemisinin in human small-cell lung carcinoma cells (Sadava et al., 2002) which shows the importance of the interactions of artemisinin with hemin of haemoglobin or myoglobin in its anticancer effects. Moreover our studies had recommended the suitability of dihydroartemisinin fo prevention of cancer or the treatment of early (trace) stage of cancer (Nedosa et al., 2011b).

\section{REFERENCES}

Anastasia, U.N.U., 2011. Dihydroartemisininstimulated proliferation of rat intestinal smooth muscles and glands. Inventi Journals Pvt. Ltd.

Nedosa, U.A.U., P.A. Akah, K.S. Nedosa, I.K. Onyedibe and I.V. Nedosa et al., 2011a. Dihydroartemisinin-stimulated widening of the caliber of blood vessels of the coronary circulation in rats. Inventi Journals Pvt. Ltd. 
Nedosa, U.A.U., P.A. Akah, K.S. Nedosa, I.K. Onyedibe and I.V. Nedosa et al., 2011b. Direct stimulatory effects of oral dihydroartemisinin on red and white blood cell stem cells in the lungs of rats. Inventi Journals Pvt. Ltd.

Anastasia, U.N.U., A.P. Achunike, N.K. Stanislaus, O.I. Kenneth and N.I. Valentine et al., 2011. Two types of inhibitory occupation and activity of oral dihydroartemisinin on cardiac muscles of wistar albino rats. Inventi Journals Pvt. Ltd.

Anastasia, N.U., S. Mohammed, N.K. Stanislaus, N. Goddy and I.K. Onyedibe et al., 2012. Extra-bone marrow sites of haemopoeisis: Dihydroartemisinin effects in wistar albino rats. Am. J. Applied Sci., 9: 7-12.

Asawamahaskda, W., I. Ittratt, Y.M. Pu, H. Ziffer and S.R. Meshnick, 1994. Reaction of antimalarial endoperoxides with specific parasite proteins. Antimicrob. Agents Chemother, 38: 1854-1858.

Chen, H.H., H.J. Zhou and X. Fang, 2003. Inhibition of human cancer cell line growth and human umbilical vein endothelial cell angiogenesis by artemisinin derivatives in vitro. Pharmacol. Res., 48: 231-236. PMID: 12860439

Cumming, J.N., P. Ploypradith and G.H. Posner, 1997. Antimalarial activity of artemisinin (qinghaosu) and related trioxanes: Mechanism(s) of action. Adv. Pharmacol., 37: 253-297. PMID: 8891104

Dhingra, V., K.V. Rao and M.L. Narasu, 2000. Current status of artemisinin and its derivatives as antimalarial drugs. Life Sci., 66: 279-300. PMID: 10665980

Efferth, T., H. Dunstan, A. Sauerbrey, H. Miyachi and C.R. Chitambar, 2001. The anti-malarial artesunate is also active against cancer. Int. J. Oncol., 18: 767773. PMID: 11251172
Efferth, T., M. Darvey, A. Olbrich, G. Rucher and E. Gebbart et al., 2002. Activity of drugs from traditional Chinese medicine toward sensitive and MDR1- or MRP1-overexpressing multidrugresistant human CCRF-CEM leukemia cells. Blood Cell Mol. Dis., 28: 160-168. PMID: 12064912

Kim, K.J., B. Li, J. Winer, M. Armanini and N. Gillett et al., 1993. Inhibition of vascular endothelial growth factor-induced angiogenesis suppresses tumour growth in vivo. Nature, 362: 841-844. PMID: 7683111

Lai, H. and N.P. Singh, 1995. Selective cancer cell cytotoxicity from exposure to dihydroartemisinin and holotransferrin. Cancer Lett., 91: 41-46. PMID: 7750093

Sadava, D., T. Phillips, C. Lin and S.E. Kane, 2002. Transferrin overcomes drug resistance to artemisinin in human small-cell lung carcinoma cells. Cancer Lett., 179: 151-156. PMID: 11888669

Singh, N.P. and H. Lai, 2001. Selective toxicity of dihydroartemisinin and holotransferrin toward human breast cancer cells. Life Sci., 70: 49-56. PMID: 11764006

Uchechukwu, U.N., N. Goddy, S.N. Kenechi, A.A. Peter and I.O. Theophilus et al., 2011. Respiratory tract-widening effects of dihydroartemisinin in wistar albino rats. Am. J. Pharmacol. Toxicol., 6: 46-48. DOI: 10.3844/ajptsp.2011.46.48

WHO, 1994. The Role of Artemisinin and its Derivatives in the Current Treatment of Malaria (1994-1995). 1st Edn., World Health Organization, Geneva, pp; 49.

Woerdebag, H.J., T.A. Moskal, N. Pras, T.M. Malingre and F.S. El-Feraly et al., 1993. Cytotoxicity of artemisinin-related endoperoxides to Ehrlich ascites tumor cells. J. Nat. Prod., 56: 849-859. PMID: 8350087

Woodrow, C.J., R.K. Haynes and S. Krishna, 2005. Artemisinins. Postgrad. Med. J., 81: 71-78. DOI: 10.1136/pgmj.2004.028399 